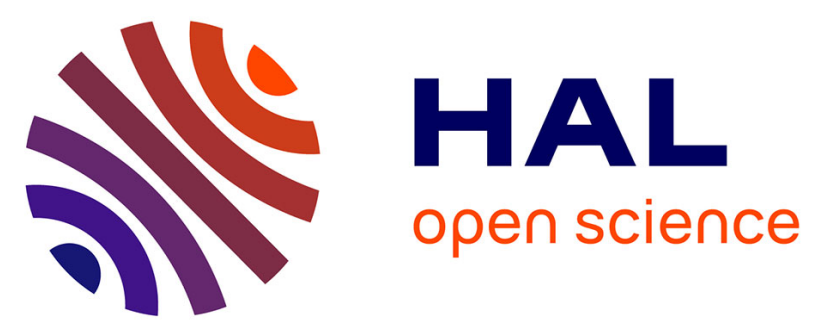

\title{
Thermodynamics of slush and snow-ice formation in the Antarctic sea-ice zone
}

Mathilde Jutras, Martin Vancoppenolle, Antonio Lourenço, Frédéric Vivier, Gauthier Carnat, Gurvan Madec, clement rousset, Jean-Louis Tison

\section{- To cite this version:}

Mathilde Jutras, Martin Vancoppenolle, Antonio Lourenço, Frédéric Vivier, Gauthier Carnat, et al.. Thermodynamics of slush and snow-ice formation in the Antarctic sea-ice zone. Deep Sea Research Part II: Topical Studies in Oceanography, 2016, 131, pp.75-83. 10.1016/j.dsr2.2016.03.008 . hal01303755

\section{HAL Id: hal-01303755 \\ https://hal.sorbonne-universite.fr/hal-01303755}

Submitted on 18 Apr 2016

HAL is a multi-disciplinary open access archive for the deposit and dissemination of scientific research documents, whether they are published or not. The documents may come from teaching and research institutions in France or abroad, or from public or private research centers.
L'archive ouverte pluridisciplinaire HAL, est destinée au dépôt et à la diffusion de documents scientifiques de niveau recherche, publiés ou non, émanant des établissements d'enseignement et de recherche français ou étrangers, des laboratoires publics ou privés. 


\section{Abstract}

Snow over Antarctic sea ice is often flooded by brine or seawater, particularly in spring, forming slush and snow ice. Here, we evaluate the representation of the thermodynamics of slush and snow-ice formation in large-scale sea-ice models, using laboratory experiments $(\mathrm{NaCl}$ solutions poured into grated ice in an isolated container). Scaling analysis highlights latent heat as the main term of the energy budget. The temperature of the new sea ice immediately after flooding is found very close to the saltwater freezing point, whereas its bulk salinity is typically $>20 \mathrm{~g} / \mathrm{kg}$. Large-scale sea-ice models faithfully represent such physics, yet the uncertainty on the origin of flooding saltwater impacts the calculated new ice temperature, because of the different salinities of seawater and brine. The laboratory experiments also suggest a potential limitation to the existing physical representations of flooding: for brine fractions $>60 \%$, ice crystals start floating upon saltwater. Natural sea-ice observations, suggest that the isolated system assumption holds for a few hours at most, after which rapid heat and salt exchanges mostly destroy the initial flooding signature on temperature and salinity. A small footprint on ice salinity remains however: natural snow ice is found $3-5 \mathrm{~g} / \mathrm{kg}$ more saline than other forms of sea ice.

Preprint submitted to Deep-Sea Research II

March 22, 2016 
9 Keywords: snow ice, Antarctic, slush, thermodynamics

\section{Introduction}

The Antarctic sea-ice environment is highly dynamic, characterized by the frequent passage of storms (Worby et al., 1998), the influence of ocean waves (Squire, 2007) and substantial precipitation (Bromwich et al., 2004). Such conditions force the redistribution and mixing of pure ice, snow, seawater, brine and meltwater within the pack, as indicated by the diverse texture and isotopic signals in Antarctic compared to Arctic sea ice (Jeffries et al., 1997). The processes mixing ice, snow and water are mainly the flooding of snow by seawater and brine (e.g. Lytle and Ackley, 1996), the percolation of meltwater through the brine network with possible stagnation and refreezing within the ice (e.g. Kawamura et al., 1997), and ice ridging, which traps seawater among broken ice blocks (e.g. Leppäranta et al., 1995; Tin and Jeffries, 2003; Williams et al., 2014). In turn, the main Antarctic sea ice halo-thermodynamic regimes (Haas et al., 2001; Kawamura et al., 1997; Maksym and Jeffries, 2000; Saenz and Arrigo, 2012) are more diverse than the standard Arctic modeling view suggests (e.g. Maykut and Untersteiner, 1971).

In particular, flooding of the snow base is widespread in the Antarctic seaice zone, fostered by two specificities: relatively small ice thickness (Worby et al., 2008) and abundant snowfall, often exceeding $500 \mathrm{~mm}$ of water equivalent per year (Bromwich et al., 2004; Jeffries et al., 2001). As a result, the snow-ice interface is often pushed below sea level (negative freeboard), hydraulically forcing the infiltration of saltwater into snow, forming slush and snow ice (Eicken et al., 1994; Lytle and Ackley, 1996). The flooding water can be brine moving upwards, if the ice is permeable (Golden et al., 1998), or seawater moving laterally from cracks and floe edges (Massom et al., 2001). The snow-ice thickness is highest in late winter 
in coastal regions of the East Antarctic sector and of the Amundsen and Bellingshausen Seas (Maksym and Markus, 2008). In the Northern Hemisphere, there are much fewer reports of slush and snow ice, because of generally thicker ice and much lower precipitation, as confirmed in large-scale model sea ice hindcasts (e.g., Vancoppenolle et al., 2009). Yet snow ice has been reported near the coast of Svalbard (Høyland, 2009) and in the Baltic Sea (Leppäranta, 1983). Slush and snow ice contribute to about a third of the total Antarctic sea-ice mass production, as suggested by oxygen isotope analyses (Jeffries et al., 1997; Worbv et al., 1998), satellite (Maksym and Markus, 2008) and model-based (Vancoppenolle et al., 2009) estimates.

Slush and snow-ice formation has long been represented in large-scale sea-ice models as a single process (e.g., Fichefet and Morales Maqueda, 1997; Hunke et al., 2015; Vancoppenolle et al., 2009). The rate of snow-ice growth is determined by the fraction of snow depth lying below sea level, as determined by isostasy (Leppäranta, 1983). The initial temperature and salinity of the newly formed slush / snow ice derive from salt and energy conservation as proposed by Schmidt et al. (2004). This model representation of snow-ice thermodynamics has not been evaluated with observations, however. Process studies with one-dimensional models have focused on the rate of snow-ice formation (e.g. Crocker and Wadhams, 1989; Leppäranta, 1983), on the impact of the brine flow on the salinity evolution (Maksvm and Jeffries, 2000, 2001; Saenz and Arrigo, 2012), whereas Saenz and Arrigo (2012) also treat the impact of slush desalination on the growth of ice algae. Yet the energetic aspects of flooding events and their impact on the initial slush and snow-ice thermodynamic properties, have not been investigated. In this context, the present study aims (i) to describe the energy and salt budget of slush and snow-ice formation; and (ii) to evaluate the thermodynamic computation of initial slush and snow-ice properties from 
large-scale sea-ice models, using laboratory experiments.

We first describe (Section 2) two approaches for the energy budget of slush and snow-ice formation. The first one simplifies the energy budget but is not fully energyconserving. The second one is based on energy and salt conservation (Schmidt et al., 2004) and used in large-scale sea ice models. The realism of both approaches is investigated through laboratory experiments. In these experiments, described in Section 3, a $\mathrm{NaCl}$ solution is poured within grated ice (a lab analog for snow) in a cryogenic container, varying the physical input conditions (the temperature of both snow and saltwater, the saltwater salinity, and the grated ice density). Both theoretical approaches suggest that the temperature of the initial slush is very close to the freezing point of the flooding saltwater, which is confirmed experimentally (Section 4). Yet we find a significant limit in the validity of both representations of the process: if the liquid fraction exceeds $60 \%$, the ice crystals start to float, stratifying the system into two layers with distinct properties. In Section 5, results are put in the context of natural sea-ice observations. In Section 6, we provide elements of discussion and conclude this paper.

\section{Theoretical Background}

As assumed in large-scale sea-ice models, freshly formed slush and snow ice are not explicitly distinguished: both are considered as sea ice, characterized by temperature $\left(T\right.$, in ${ }^{\circ} \mathrm{C}$ ) and bulk salinity $(S$, in $\mathrm{g} / \mathrm{kg}$ ) (Bitz and Lipscomb, 1999; Vancoppenolle et al., 2010). Hence, and unless otherwise stated, we will hereafter use snow ice both for slush and snow ice. The transformation of a mixture of snow and saltwater into sea ice is considered (see illustrations of the process as occurring in the field in Fig. 17 and as conceptualized in Fig. 1b). The initial state of the system is characterized by a snow mass $m_{s}$, with temperature $T_{s}$, zero salinity, and 
density $\rho_{s}$, homogeneously flooded by saltwater with mass $m_{w}$, temperature $T_{w}$ and salinity $S_{w}$. The final state is a mass of sea ice $m_{i}$ with temperature $T_{i}$, salinity $S_{i}$ and density $\rho_{i}$. Note that we neither consider the neighbouring dry snow above or sea ice below (see Fig. 1a), nor the pathway, nor the origin of the flooding water.

\subsection{The freezing-point approach}

The first approach to derive the snow-ice temperature shortly after formation is based on physical reasoning. For the snow temperatures $\left[-10^{\circ} \mathrm{C}, 0^{\circ} \mathrm{C}\right]$ and saltwater temperatures $\left[-2^{\circ} \mathrm{C}, 2^{\circ} \mathrm{C}\right]$ encountered in nature, the Stefan number $c T / L$ is generally small $(<0.05)$. Therefore, the sensible heat stored in saltwater and snow is generally much smaller than the latent heat released (absorbed) due to internal freezing (melting). Hence, only a small amount of internal freezing (melting) is required to compensate for the sensible heat of the two initial phases. Because of the small internal melting or freezing, the salinity of the brine incorporated in new snow ice is close to the flooding saltwater salinity $S_{w}$. Assuming thermal equilibrium and linear liquidus, one finds that the temperature of the new snow ice is simply:

$$
T \approx T^{f r}=-\mu S_{w}
$$

where $\mu$ gives the linear dependence of the freezing temperature as a function of water salinity and differs for seawater and $\mathrm{NaCl}$ solutions (see Tab. 11). In this view, the new snow-ice temperature is the freezing point of the flooding saltwater $T^{f r}$. Whereas this freezing point approach seems suitable for a physical description of the process, it may not be valid in all conditions. In addition, because sensible heat is neglected, the freezing point approach is not energy-conserving, and hence not appropriate for large-scale models. 


\subsection{The fully energy- and salt-conserving approach}

In most sea-ice models, the temperature and salinity of solid and liquid mixtures right after formation derive from mass, salt and energy conservation equations (Schmidt et al., 2004). Following this generic approach, hereafter referred to as fullyconserving, the enthalpy of snow ice is computed as the sum of the enthalpies of snow and flooding saltwater (Hunke et al., 2015; Vancoppenolle et al., 2009). From enthalpy, the ice temperature can be retrieved. The new snow-ice salinity (on which enthalpy also depends) derives from the original salt content of saltwater. This computation is shortly described in this Section. Details are given in Appendix A.

In models, flooding is typically conditioned by negative freeboard, following Leppäranta (1983), generally assuming that seawater floods the snow (Fichefet and Morales Maqueda, 1997; Hunke et al., 2015; Vancoppenolle et al., 2009), whereas in reality both brine and seawater contribute, depending on environmental conditions (Maksym and Jeffries, 2000; Massom et al., 2001). As the salinity of the flooding saltwater is treated as an independent variable, the fully-conserving approach encompasses both cases.

The following working hypotheses are made.

H1: The system is isolated, i.e. mass, salt and energy are conserved. Note that in sea-ice models, this hypothesis is only used to compute initial $T$ and $S$, and relieved elsewhere, enabling external exchanges of heat and salt.

H2: The system is homogeneous and in thermodynamic equilibrium by the end of the transformation, with single values for $T_{i}$ and $S_{i}$.

H3: The flooding water entirely fills the air interstices initially present in the snow.

The two relevant equations for salt and energy conservation are (see Appendix A 
for a complete derivation):

$$
\begin{aligned}
S_{i} & =\phi_{a} S_{w} \\
E_{i}\left(T_{i}, S_{i}\right) & =\phi_{i} E_{s}\left(T_{s}\right)+\phi_{a} E_{w}\left(T_{w}\right)
\end{aligned}
$$

where $\phi_{i}=\rho_{s} / \rho_{i}$ and $\phi_{a}=\left(\rho_{i}-\rho_{s}\right) / \rho_{i}$ are respectively the ice and air fractions in the pre-existing snow, and $E_{i}, E_{s}$ and $E_{w}$ are the specific enthalpies (in $\mathrm{J} / \mathrm{kg}$ ) of sea ice, snow and saltwater, respectively (Schmidt et al., 2004). The system of equations (2) thermodynamically describes new sea-ice formation due to flooding, giving $S_{i}$ and $T_{i}$, as a function of $T_{w}, S_{w}, T_{s}$ and $\rho_{s}$. The enthalpy-temperature diagram (Fig. 21) graphically illustrates the links between the energy budget and temperature. In agreement with the physical scaling of Section 2.1, the E-T diagram indicates that the latent heat dominates the energy budget. In the rare case snow density would exceed $\approx 2 / 3 \rho_{i} \approx 600 \mathrm{~kg} / \mathrm{m}^{3}$, sensible heat storage in snow would significantly contribute to the energy budget as well.

Snow density over Antarctic sea ice features large variations in the 100-600 $\mathrm{kg} / \mathrm{m}^{3}$ range, with typical values around 320-360 kg/m $\mathrm{m}^{3}$ (Massom et al., 2001). Deep snow is generally denser. Since the value $\rho_{s}=330 \mathrm{~kg} / \mathrm{m}^{3}$ introduced by Maykut and Untersteiner (1971) is still a standard value in present-day sea ice models (Bitz and Lipscomb, 1999; Vancoppenolle et al., 2009), we used it here as a basis for theoretical computations (e.g. Fig. 2 and 3 ). The chosen value of $950 \mathrm{~kg} / \mathrm{m}^{3}$ for sea ice density corresponds to $\sim 35 \%$ of brine fraction, substantially higher than pure ice density $\left(917 \mathrm{~kg} / \mathrm{m}^{3}\right)$.

The salinity equation is trivial, whereas the enthalpy equation can be rewritten as a second-order algebraic equation for sea-ice temperature, with a unique physically- 
acceptable solution:

$$
\begin{gathered}
0=c_{0} T_{i}^{2}-A\left(T_{w}, S_{w}, T_{s}\right) \cdot T_{i}-\phi_{a} L \mu S_{w} \\
A\left(T_{w}, S_{w}, T_{s}\right)=\phi_{i} c_{0} T_{s}+\phi_{a}\left[L+c_{w} T_{w}+\left(c_{w}-c_{0}\right) \mu S_{w}\right] .
\end{gathered}
$$

Eq. 3 gives the fully-conserving solution $T^{\text {cons }}$ for the new snow-ice temperature. The dependence of $T^{\text {cons }}$ on all four parameters is illustrated with the black lines in Figure 3 .

A first-order, analytically useful solution that reasonably approximates $T^{\text {cons }}$ can be derived by dropping the quadratic and the $\left(c_{w}-c_{0}\right) \mu S_{w}$ terms in the temperature equation:

$$
T_{i} \approx-\mu S_{w}\left[1-\rho_{s} /\left(\rho_{i}-\rho_{s}\right) \cdot \frac{c_{0} T_{s}}{L}-\frac{c_{w} T_{w}}{L}\right]
$$

If the Stefan number $(c T / L)$ is small, eq. 4 further reduces to $T_{i} \approx-\mu S_{w}$, i.e. the freezing point solution.

\section{Laboratory Experiments}

The idealized view of snow-ice formation described in Section 2 was experimentally emulated by enforcing the physical hypotheses $\mathbf{H 1 - H 3}$, using the following experimental design :

1. Place grated ice with known volume, mass (hence density) and temperature in an insulated cryogenic container.

2. Pour saltwater of known temperature and salinity until all grated ice crystals are visibly in contact with water.

3. Let the system equilibrate.

4. Measure the resulting saltwater ice properties (temperature and salinity). 
The experimental setup is schematically illustrated in Figure 1c.

Grated ice, as snow, is made up of air and small ice chunks, and used here as an easily produced lab analog for snow. The structure of grated ice and of synthetic snow ice was examined in a cold room, photographed and compared to natural snow ice from the SIMBA campaign (Lewis et al., 2011), see Figure 4, Grated ice grains are larger and more acute than for natural snow (Fig. 4a), which has a visible impact on the resulting synthetic snow-ice structure (Fig. 4b-c) as compared with natural snow ice (Fig. 44d). Despite these differences, grated ice with a grain size $<2 \mathrm{~mm}$ is, as far as heat diffusion is concerned, comparable to snow at the scale of our experiment $(10 \mathrm{~cm})$.

The experiment was repeated at various grated ice and water temperatures (from $-26.3^{\circ} \mathrm{C}$ to $-0.8^{\circ} \mathrm{C}$ and from $-1.2^{\circ} \mathrm{C}$ to $23.7^{\circ} \mathrm{C}$, respectively), grated ice densities (from $332 \mathrm{~kg} / \mathrm{m}^{3}$ to $582 \mathrm{~kg} / \mathrm{m}^{3}$ ) and water salinities (from $22 \mathrm{~g} / \mathrm{kg}$ to $69 \mathrm{~g} / \mathrm{kg}$ ), see Table S1. Although some of these salinity and temperature values may seem off the observed range, they enable a complete experimental check of the two models over a wide range of situations. In particular, grated ice density is larger than typical snow values (max. $\sim 390 \mathrm{~kg} / \mathrm{m}^{3}$ according to Massom et al. (2001)). Grated ice is hard to control experimentally (see Appendix B), however.

This setup fulfills our hypotheses. H1 (isolated system) was achieved by using a highly isolated cryogenic container (KGW-Isotherm) and by correcting the temperature increase due to a small heat input over the time of the experiment. The mean correction is $0.63^{\circ} \mathrm{C}$ for a 20 minute experiment, as retrieved from control runs measuring how water temperature increases over long periods. H2 (homogeneous system at equilibrium) was achieved by delicately mixing to avoid stratification and interference with ice growth until the temperature stabilized. The experiments with presumed stratification were removed from the analysis (see next section). H3 (ap- 
propriate water volume) was enforced by pouring water until all grated ice interstices were filled with saltwater. More details on the experimental setup, $T$ and $S$ measurements techniques and precisions are provided in Appendix B.

\section{Results}

We now analyze the equilibrium ice temperature, salinity and brine fraction from theory (Section 2) and experimental results. The ice salinity is trivially determined from saltwater salinity and snow density (eq. 2a). In the lab, the ice salinity is practically constrained by the amount of saltwater poured into the container. Figure 5 shows the experimental snow-ice temperature versus the fully-conserving computation (eq. 3). Figure 6 shows how the experimental snow-ice temperature depends on water salinity, water temperature and snow temperature. All the experimental results $\left(T_{w}, T_{s}, \rho_{s}, S_{w}, T_{i}\right)$ are given in Supplementary Table $\mathbf{S 1}$

\subsection{Temperature}

In all of our experiments, snow is initially colder than water, as is most frequently the case in nature. Therefore, once both phases are mixed, the ice grains gain heat, whereas saltwater loses heat and some water molecules freeze on existing ice crystals. This releases latent heat and increases the salinity of the remaining saltwater. The thermistors, initially lying in the ice crystals, typically record a rapid temperature increase. Temperature stabilizes within 20 minutes. Salt diffuses much more slowly than heat and sets this time scale towards equilibrium $\left(t \approx L^{2} / D \approx 20 \mathrm{~min}\right.$, with $D=10^{-9} \mathrm{~m}^{2} / \mathrm{s}$ the molecular diffusivity of salt and $L \approx 1 \mathrm{~mm}$ for grated ice grains, see Fig. 4).

The temperatures retrieved from the fully-conserving approach ( $T^{\text {cons }}$, eq. 3), using the experimental values of $T_{s}, T_{w}, \rho_{s}, S_{w}$ as input parameters, closely match 
the experimental equilibrium temperatures (Fig. 5 and Tab. S1), with low bias $\left(0.07^{\circ} \mathrm{C}\right)$ and root mean square error $(\mathrm{RMSE})\left(0.19 \pm 0.22^{\circ} \mathrm{C}\right)$. The freezing point temperatures $T^{f r}$, based on $S_{w}$ alone, are slightly less precise, with a negative bias of $-0.28^{\circ} \mathrm{C}$ and larger RMSE $\left(0.36 \pm 0.48^{\circ} \mathrm{C}\right)$. Despite the small differences between $T^{f r}$ and $T^{c o n s}$, their value is very close for a wide range of input physical parameters (see Fig. 3, dotted lines vs full lines). Indeed, when linearly regressing the retrieved $T^{\text {cons }}$ against the experimental $S_{w}$, the linear regression coefficient found is $0.053 \pm 0.002$ ${ }^{\circ} \mathrm{C} /\left(\mathrm{g} \cdot \mathrm{kg}^{-1}\right)$, close to the theoretical linear liquidus coefficient $\mu=0.0598^{\circ} \mathrm{C} /\left(\mathrm{g} \cdot \mathrm{kg}^{-1}\right)$ for $\mathrm{NaCl}$ ice (see Fig. 6a).

Physically speaking, the strong control of the equilibrium temperature by the water salinity confirms that the largest energetic buffer in the system is the release (uptake) of latent heat by internal freezing (melting) - in direct association with $S_{w}$ - whereas changing $T_{s}$ or $T_{w}$ requires only a small amount of heat. As a result, $T^{c o n s}$ and $T^{f r}$ are close (as long as the Stefan number is small and snow density is $<600 \mathrm{~kg} / \mathrm{m}^{3}$ (see Fig. 3). In the enthalpy-temperature diagram (Fig. 2), the slope of $E_{i}$ is nearly vertical close to freezing, which induces that $T_{i} \approx T^{f r}$. There are two additional consequences to keep in mind. First, the temperature of the newly formed snow ice can be lower than that of the pre-existing saltwater and snow (Table S1). Second, the $T_{w}$ value above which the sensible heat stored in saltwater is large enough to melt all snow is very high $\left(>40^{\circ} \mathrm{C}\right)$. This is why experiments with water at room temperature were possible and performed.

As expected, the temperature of the forming sea ice increases with $T_{w}$ and $T_{s}$. However, because the Stefan number is small, these dependencies are small (see Fig. 6b-c), as predicted by the fully-conserving approach (eq. 31): $T^{\text {cons }}$ changes by less than $0.05^{\circ} \mathrm{C}$ per degree of change in $T_{w}$ or $T_{s}$.

If $\rho_{s}>600 \mathrm{~kg} / \mathrm{m}^{3}$, the fully-conserving approach predicts a significant impact 
of the snow and saltwater temperature on $T_{i}$, in contrast with the freezing point approach (Fig. 3). Density values larger than $582 \mathrm{~kg} / \mathrm{m}^{3}$ were not tested, however, and a minor influence of density on experimental results is indeed observed.

\subsection{Brine fraction, cohesion and ice crystals flotation}

With the linear liquidus assumption, brine fraction is given by $\phi_{l}=-\mu S_{i} / T_{i}$ (Ono, 1967). Combining the first-order temperature solution (eq. (4) and salt conservation (eq. 2al), one gets

$$
\phi_{l} \approx \phi_{a}
$$

as suggested in Section 2 for small Stefan number values.

The full model solution for brine fraction (color contours in Fig. 3) uses the computed value of $S_{i}$ (eq. 2a) and $T_{i}$ (eq. 3) and does not markedly differ from $\phi_{a}$ : brine fraction is practically determined by snow density alone and differences from the air fraction in the pre-existing snow are very small $(<0.05$, Fig. 3i $)$.

Brine fraction was not measured during our experiments, but can be diagnosed from $-\mu S_{i} / T_{i}$. Changes in the cohesion of the experimental snow ice were observed depending on brine fraction, Below $\phi_{l}=50 \%$, the synthetic sea ice was wet and permeable but consolidated. In the range $50 \%<\phi_{l}<60 \%$, the ice pieces became mobile and could easily be stirred, but cohesion was strong enough to resist buoyancy (cohesive slush). Above $\phi_{l}=60 \%$, the slush mixture had no more cohesion (loose slush) and ice crystals started to float (as shown by pictures in Fig. 7). Flotation implies the violation of $\mathbf{H 2}$ : the system stratifies and is no more homogeneous. Indeed, experimental runs with $\phi_{l}>60 \%$ give temperatures outside model predictions. 


\section{Natural sea ice observations from the SIMBA experiment}

To see how the snow-ice salinities and temperatures obtained from the enthalpy conservation calculations compare with what is observed in a natural context, we analyze ice temperature and salinity data from ice core sections in a floe that underwent occasional flooding during the SIMBA (Sea Ice Mass BAlance of the Antarctic) research program, which took place in the Bellingshausen Sea from September 25 to October 24, 2007 (Lewis et al., 2011). The ice-temperature profile was measured in drill holes immediately after core extraction, texture was retrieved from thin sections, whereas salinity and oxygen isotope data were obtained from melted $5 \mathrm{~cm}$-thick core sections (see Lewis et al., 2011, for more details on sampling and methods). 250 ice core sections from 13 cores taken at Inbound, Brussels and Liège sites were analyzed.

A sample was classified as snow ice if its texture was granular and its $\delta^{18} O$ was $<-2 \%$, which corresponds to $20 \%$ of ice with meteoric origin (Jeffries et al., 1997). Core sections were classified as snow ice (19 samples), granular ice (144), columnar ice (87). All identified snow-ice samples lie in the upper third of the ice. A slush sample is also included in the analysis (Lewis et al., 2011). The characteristics of this sample are similar to those reported by other investigators in the Weddell Sea (Lytle and Ackley, 1996) and in the East Antarctic sector (Massom et al., 1998).

Each sample was represented in a T-S diagram (Fig. 8), with a different symbol for each ice type. Only the slush sample (triangle) has salinity and temperature that are consistent with theoretical predictions using the fully-conserving approach (dotted red line and pink and blue bands, respectively). The snow-ice samples (filled dots) have lower salinities and generally colder temperatures than predicted. This is because the closed system assumption does not hold very long in reality: newly formed slush and snow ice exchange heat and salt with their surroundings. As some 
of the ice cores were taken 1-2 days after flooding, rapid heat and salt losses affect $T$ and $S$ and the description presented in Section 2 holds over a few hours at most.

Snow-ice samples are all significantly less saline than predictions from the energyconserving approach (Schmidt et al., 2004). Such a systematic bias supports rapid and strong desalination, in agreement with the one-dimensional simulations of Maksym and Jeffries (2000, 2001) and Saenz and Arrigo (2012). Yet snow-ice samples are more saline $(8.9 \pm 2.6 \mathrm{~g} / \mathrm{kg})$ than other upper ice samples $(5.6 \pm 2.0 \mathrm{~g} / \mathrm{kg})$ and deeper ice samples $(3.8 \pm 1.2 \mathrm{~g} / \mathrm{kg})$. Finally, whether the flooding water is brine or seawater could have a specific footprint on temperature, but the SIMBA ice coring observations cannot be used to detect it: samples were collected too long after flooding, and the moment of flooding can hardly be identified.

\section{Discussion and outlook}

The simple energetic arguments and laboratory experiments presented here show that the temperature of slush or snow ice immediately after formation is very close to the freezing point of the flooding saltwater, and hence is primarily determined by the flooding saltwater salinity, Other factors, i.e. snow temperature, saltwater temperature and snow density have much smaller effects. Such physics derive from the large effect of the latent heat released (absorbed) by internal freezing (melting). The SIMBA temperature and salinity observations from ice cores (Bellingshausen Sea, spring 2007) suggest that the initial temperature and salinity of newly formed snow ice and slush hold for up to a few hours only, after which rapid heat exchanges and desalination processes destroy these initial signatures.

The description of slush and snow-ice formation used in most sea-ice models (e.g., Hunke et al., 2015; Vancoppenolle et al., 2009), based on the formalism of Schmidt et al. (2004), is appropriate to represent the energetic exchanges during 
flooding events. The agreement found here between this formulation and laboratory experiments, within $<0.1^{\circ} \mathrm{C}$ on average, strengthens the confidence in the thermodynamic basis of sea-ice models. The water temperature limit for slush survival in an isolated system is extremely high $\left(>40^{\circ} \mathrm{C}\right)$, hence the Schmidt et al. (2004) formulation can be used for virtually all situations encountered on this planet. Finally, note that the isolated system hypothesis, the most doubtable of all, is relieved in sea-ice models after the computation of slush and snow-ice initial properties: exchanges of salt and heat with the remainder of the ice are computed in a separate step. The largest remaining uncertainty is associated with the salinity of the flooding saltwater. Most large-scale sea-ice models assume that seawater floods the snow. Yet the new snow-ice temperature could be significantly lower if models assumed that brine, much more saline than seawater, floods the snow, instead of seawater, with potential impacts on basal ice growth.

Laboratory experiments indicate flotation of ice crystals for brine fractions above $60 \%$, which corresponds to snow densities below $350 \mathrm{~kg} / \mathrm{m}^{3}$. Such densities were rarely encountered in our experiments, but are frequent in nature (Massom et al., 2001), hence liquid water could be found near the snow-ice interface if enough slush is formed at a time, e.g. after a strong snow storm. Since our experiments were conducted in an idealized environment, it is hard to predict how these liquid layers would evolve in nature based on our experiments. Yet the finding of floating ice crystals above liquid water could relate to the reports of very wet conditions near the snow base (Lewis et al., 2011; Lvtle and Acklev, 1996) and relate to what has been described as "gap layers" (Ackley et al., 1979; Haas et al., 2001) - liquid layers right below the ice-snow interface. Ice crystal flotation effects are not represented in sea-ice models, but we do not envision large impacts on simulated ice thickness.

The Schmidt et al. (2004) conservation equations suggest that the snow and salt- 
water temperatures become influential for snow density above $600 \mathrm{~kg} / \mathrm{m}^{3}$. Snow would rarely be so dense in nature, but using such large values could describe the flooding of denser ice forms, such as sea ice itself. In this regime, the impact of the sensible heat contained in the pre-existing ice becomes dominant and the resulting ice temperature is much closer to the pre-existing ice temperature.

The fully-conserving approach of Schmidt et al. (2004) as presented here may also somewhat apply to retrieve the temperature of ridged ice. Ridges are also mixtures of ice and saltwater, but with large chunks of ice instead of microscopic crystals. Within ridges, however, the time scale to equilibrium would be a few days (Høyland, 2002), being governed by heat diffusion in the ice blocks and convection in the liquid voids, rather than by salt diffusion.

Several uncertainties remain regarding the representation of Antarctic seaice thermodynamics in large-scale models. Whether the latter need to capture all the halo-thermodynamic processes specific to the Antarctic sea-ice zone (Kawamura et al., 1997; Lewis et al., 2011; Lytle and Ackley, 1996) remains unclear. How brine and seawater sources contribute to flooding is not well understood, neither how the salt losses and heat exchanges shape the evolution of slush and snow ice after formation, as already pointed out (Maksym and Jeffries, 2000; Saenz and Arrigo, 2012). Our understanding could improve from natural and experimental sea-ice studies, in particular through the use of non-destructive and high frequency temperature and salinity measurements, as proposed by Notz (2005a), rather than from ice coring. 


\section{Appendix A. Computation of slush and snow-ice properties in sea-ice models}

The initial state of the system is characterized by a snow mass $m_{s}$ - with temperature $T_{s}$, zero salinity, and density $\rho_{s}$ - homogeneously flooded by an appropriate mass of saltwater $m_{w}$ with temperature $T_{w}$ and salinity $S_{w}$ (that of seawater or brine). Snow and saltwater are then mixed homogeneously. The final state is a mass of sea ice $m_{i}$ with temperature $T_{i}$ and salinity $S_{i}$.

As described in Section 2, we assume an isolated system (H1), evolving towards thermodynamic equilibrium (H2), and that the flooding water entirely fills the air initially present in the snow (H3). We further assume that the densities of snow $\left(\rho_{s}\right)$, sea ice $\left(\rho_{i}\right)$ and the latent heat of fusion of pure ice $(L)$ as well as the pure ice and saltwater heat capacities $\left(c_{0}, c_{w}\right)$ are independent of $T$ and $S$ (see Tab. 1). We also assume that the sea-ice liquidus is linear: $T=-\mu S_{b r}$, where $S_{b r}$ is brine salinity and $\mu$ corresponds to either sea ice or $\mathrm{NaCl}$ ice (see Tab. 1). This is valid as long as energetic exchanges are considered, but not for a precise computation of brine salinity (Notz, 2005b).

Following $\mathbf{H 1}$ and $\mathbf{H 2}$, the water, salt and energy conservation laws of the system read (in order):

$$
\begin{aligned}
m_{i} & =m_{s}+m_{w}, \\
m_{i} S_{i} & =0+m_{w} S_{w}, \\
m_{i} E_{i} & =m_{s} E_{s}+m_{w} E_{w}
\end{aligned}
$$

where the specific enthalpies $(\mathrm{J} / \mathrm{kg})$ of snow ice, snow and saltwater are respectively 
398

399

400

401

(Schmidt et al., 2004):

$$
\begin{aligned}
E_{s}\left(T_{s}\right) & =c_{0} T_{s}-L \\
E_{w}\left(T_{w}\right) & =c_{w} T_{w} \\
E_{i}\left(T_{i}, S_{i}\right) & =c_{0}\left(T_{i}+\mu S_{i}\right)-L\left(1+\frac{\mu S_{i}}{T_{i}}\right)-c_{w} \mu S_{i} .
\end{aligned}
$$

The expression for $E_{i}$ is based on the linear liquidus hypothesis. Using $\mathbf{H 3}$, the system of equations (A.1) can be rewritten as:

$$
\begin{aligned}
m_{w} & =\left(\rho_{i}-\rho_{s}\right) V \\
S_{i} & =\phi_{a} S_{w} \\
E_{i}\left(T_{i}, S_{i}\right) & =\phi_{i} E_{s}\left(T_{s}\right)+\phi_{a} E_{w}\left(T_{w}\right),
\end{aligned}
$$

where $\phi_{i}=\rho_{s} / \rho_{i}$ and $\phi_{a}=\left(\rho_{i}-\rho_{s}\right) / \rho_{i}$ are the ice and air fractions in the pre-existing snow, respectively. The system (A.3) thermodynamically describes new slush and snow-ice formation and gives $m_{w}, S_{i}$ and $T_{i}$, assuming that $T_{w}, S_{w}$ and $T_{s}$ are known. The first two equations are trivial. For the temperature equation, we replace the specific enthalpies in (A.3C) by their expressions from (A.2), then multiply by $T_{i}$ and replace $S_{i}$ by its expression (A.3b), giving:

$$
\begin{gathered}
0=c_{0} T_{i}^{2}-A\left(T_{w}, S_{w}, T_{s}\right) \cdot T_{i}-\phi_{a} L \mu S_{w}, \\
A\left(T_{w}, S_{w}, T_{s}\right)=\phi_{i} c_{0} T_{s}+\phi_{a}\left[L+c_{w} T_{w}+\left(c_{w}-c_{0}\right) \mu S_{w}\right] .
\end{gathered}
$$

Equation (A.4a) is quadratic in $T_{i}$, with a unique physically acceptable solution.

\section{Appendix B. Material and methods}

The main series of laboratory experiments was conducted at the Laboratoire d'Océanographie et du Climat, Paris, in June 2014. The micro-structure of grated 
ice and of synthetic snow ice was examined in a separate series of experiments in a cold room at the Laboratoire de Glaciologie, Université Libre de Bruxelles, Belgium (see Fig. 41) in January 2015.

Grated ice was obtained by grating tap water ice cubes with a professional cheese grater (Santos no. 2), with two different blades to get different densities (see Fig. 4a). Grated ice was used as an analog for snow, as it is more easily obtained, at least in Paris where the experiments took place. Grated ice density is hard to control accurately, but we obtain a range from $462-582 \mathrm{~kg} / \mathrm{m}^{3}$ and use snow from condensation in a freezer with $\rho_{s}=332-438 \mathrm{~kg} / \mathrm{m}^{3}$. Like for snow, grated ice includes ice and air, hence at macro-scales, its action on heat diffusion is similar. The grated ice grains are typically less than $\sim 3 \mathrm{~mm}$-long, only slightly larger than natural snow grains (1-2 mm Massom et al., 2001), and much smaller than the scale of the experiment (about 2L), which is important to ensure that $\mathbf{H 2}$ is verified. The grains are also more acute (Fig. 4c) than for natural snow (Fig. 4d), but this should not affect the heat diffusion. All these arguments give enough support to the use of grated ice for our purposes.

The saltwater was obtained by diluting $\mathrm{NaCl}$ caps in tap water. The salinity of this water and that of the melted synthetic snow ice were retrieved from highprecision density measurements, using a centigram precise balance and a high precision flask for volume measurement. Density $(\rho)$ was converted into salinity using the TEOS-10 software (IOC et al., 2010). The error in salinity was calculated by comparing the maximal and minimal values obtained by using $\rho \pm \Delta \rho$, where $\Delta \rho$ is the measurement uncertainty on density. The resulting typical error in salinity was $\sim 1 \mathrm{~g} / \mathrm{kg}$.

Grated ice density was derived by weighing $\sim 2 \mathrm{~L}$ of grated ice and measuring its volume with a long graduated cylinder. The uncertainty in volume estimates is on 
the order of $\Delta V \approx 50 \mathrm{~mL}$ due to (i) changes in grated ice density and loss of ice during transfer from the cylinder to the cryogenic container and (ii) irregularities at the grated ice surface. This leads to an error in $\Delta \rho_{s}$ of $\approx 30 \mathrm{~kg} / \mathrm{m}^{3}$, i.e. a few percent of the absolute value.

The saltwater temperature ranged from $-1.2^{\circ} \mathrm{C}$ to $23.7^{\circ} \mathrm{C}$, being measured with a Testo 720 digital thermometer $\left(\Delta T= \pm 0.1^{\circ} \mathrm{C}\right)$. The temperature in the cryogenic container - before and after pouring the saltwater - was measured with a homemade thermistor chain $\left(\Delta T= \pm 0.02^{\circ} \mathrm{C}\right.$, one sensor every $6 \mathrm{~cm}$, sampling every 4 seconds). Both temperature sensors were calibrated using a Sea Bird temperature logger $(\Delta T=$ $\pm 10^{-3 \circ} \mathrm{C}$ ) as a standard measure.

\section{Aknowledgments}

European Union funding through BISICLO (FP7 Career Integration Grant 321938) is gratefully acknowledged. For SIMBA data, please contact Jean-Louis Tison (jtison@ulb.ac.be). Thanks as well to François Fripiat for lending us his precious professional cheese grater. Anonymous reviewers made relevant, significant and highly appreciated suggestions that really helped in improving this manuscript.

\section{References}

Ackley, S.F., Buck, K., S.Taguchi, 1979. Standing crop of algae in the sea ice of the Weddell Sea region. Deep-Sea Research, Part A 26, 269-281.

Bitz, C.M., Lipscomb, W.H., 1999. An energy-conserving thermodynamic model of sea ice. Journal of Geophysical Research 104, 15,669-15,677. 
Bromwich, D.H., Guo, Z., Bai, L., Chen, Q.S., 2004. Modeled Antarctic precipitation. part i: Spatial and temporal variability. Journal of Climate 17, 427-447. doi: $10.1175 / 1520-0442(2004) 017<0427$ :MAPPIS $>2.0$. CO ; 2.

Crocker, G.B., Wadhams, P., 1989. Modelling Antarctic fast-ice growth. Journal of Glaciology 35, 3-8. doi:10.3189/002214389793701590.

Eicken, H., Lange, M.A., Wadhams, P., 1994. Characteristics and distribution patterns of snow and meteoric ice in the Weddell Sea and their contribution to the mass balance of sea ice. Annales Geophysicae 12, 80-93.

Fichefet, T., Morales Maqueda, M.A., 1997. Sensitivity of a global sea ice model to the treatment of ice thermodynamics and dynamics. Journal of Geophysical Research 102, 12,609-12,646.

Golden, K.M., Ackley, S.F., Lytle, V.I., 1998. The percolation phase transition in sea ice. Science 282, 2238-2241. doi:10.1126/science.282.5397.2238.

Haas, C., Thomas, D.N., Bareiss, J., 2001. Surface properties and processes of perennial Antarctic sea ice in summer. Journal of Glaciology 47, 613-625. doi:10.3189/172756501781831864.

Høyland, K.V., 2002. Consolidation of first-year sea ice ridges. Journal of Geophysical Research 107, 3062. doi:10.1029/2000JC000526.

Høyland, K.V., 2009. Ice thickness, growth and salinity in Van Mijenfjorden, Svalbard, Norway. Polar Research 28, 339-352. doi:10.1111/j.1751-8369.2009.00133.x. 
Hunke, E.C., Lipscomba, W.H., Turner, A.K., Jeffery, N., Elliott, S., 2015. CICE: the Los Alamos sea ice model documentation and software user's manual version 5.1. Technical Report, Los Alamos National Laboratory, Los Alamos, New Mexico.

IOC, SCOR, IAPSO, 2010. The international thermodynamic equation of seawater - 2010: Calculation and use of thermodynamic properties. Intergovernmental Oceanographic Commission, Manuals and Guides 56, UNESCO.

Jeffries, M., Worby, A., Morris, K., Weeks, W.F., 1997. Seasonal variations in the properties and structural composition of sea ice and snow cover in the Bellingshausen and Amundsen Seas, Antarctica. Journal of Glaciology 43, 138-151.

Jeffries, M.O., Krouse, H.R., Hurst-Cushing, B., Maksym, T., 2001. Snow-ice accretion and snow-cover depletion on Antarctic first-year sea-ice floes. Annals of Glaciology 33, 51-60. doi:10.3189/172756401781818266.

Kawamura, T., Ohshima, K.I., Takizawa, T., , Ushio, S., 1997. Physical, structural and isotopic characteristics and growth processes of fast sea ice in Lützow-Holm Bay, Antarctica. Jounal of Geophysical Research 102, 3345-3355.

Leppäranta, M., 1983. A growth model for black ice, snow ice and snow thickness in subarctic basins. Nordic Hydrology 14, 59-70. doi:10.2166/nh.1983.006.

Leppäranta, M., Lensu, M., Witch, P.K.B., 1995. The life story of a first-year sea ice ridge. Old Regions Science and Technology 23, 279-290. doi: $10.1016 / 0165-232 X(94) 00019-\mathrm{T}$.

Lewis, M.J., Tison, J.L., Weissling, B., Delille, B., Ackley, S., Brabant, F., Xie, H., 2011. Sea ice and snow cover characteristics during the winter-spring transition in 
the Bellingshausen Sea: An overview of SIMBA 2007. Deep Sea Research (II) 58, 1019-1038. doi:10.1016/j.dsr2.2010.10.027.

Lytle, V., Ackley, S., 1996. Heat flux through sea ice in the Western Weddell Sea: Convective and conductive transfer processes. Journal of Geophysical Research $101,8853-8868$.

Maksym, T., Jeffries, M., 2001. Phase and compositional evolution of the flooded layer during snow-ice formation on Antarctic sea ice. Annals of Glaciology 33, $37-44$.

Maksym, T., Jeffries, M.O., 2000. A one-dimensional percolation model of flooding and snow ice formation on Antarctic sea ice. Journal of Geophysical Research 105, $26,313-26,331$.

Maksym, T., Markus, T., 2008. Antarctic sea ice thickness and snow-to-ice conversion from atmospheric reanalysis and passive microwave snow depth. Journal of Geophysical Research 113. doi:10.1029/2006JC004085.

Massom, R.A., Eicken, H., Haas, C., Jeffries, M.O., Drinkwater, M.R., Sturm, M., Worby, A.P., Wu, X., Lytle, V.I., Ushio, S., Morris, K., Reid, P.A., Warren, S.G., Allison, I., 2001. Snow on Antarctic sea ice. Review of Geophysics 39, 413-445.

Massom, R.A., Lytle, V., Worby, A.P., Allison, I., 1998. Winter snow cover variability on East Antarctic sea ice. Jounal of Geophysical Research 103, 24,837-24,855.

Maykut, G.A., Untersteiner, N., 1971. Some results from a time-dependent thermodynamic model of sea ice. Journal of Geophysical Research 76, 1550-1575. 
Notz, D., 2005a. A non-destructive method for measuring the salinity and solid fraction of growing sea ice in situ. Journal of Glaciology 51, 159-166. doi:10.3189/172756505781829548.

Notz, D., 2005b. Thermodynamic and fluid-dynamical processes in sea ice. Ph.D. thesis, University of Cambridge .

Ono, N., 1967. Physics of snow and ice, chap. Specific heat and heat of fusion of sea ice. Institute of Low Temperature Science, Hokkaido, Japan , 599-610.

Saenz, B.T., Arrigo, K.R., 2012. Simulation of a sea ice ecosystem using a hybrid model for slush layer desalination. Journal of Geophysical Research 117, 1-20. doi:10.1029/2011JC007544.

Schmidt, G., Bitz, C.M., Mikolajewicz, U., Tremblay, L.B., $2004 . \quad$ Iceocean boundary conditions for coupled models. Ocean Modelling 7, 59-74. doi:10.1016/S1463-5003(03)00030-1.

Squire, V.A., 2007. Of ocean waves and sea-ice revisited. Cold Regions Science and Technology 49, 110-133. doi:10.1016/j.coldregions.2007.04.007.

Tin, T., Jeffries, M., 2003. Morphology of deformed first-year sea ice features in the Southern Ocean. Cold Regions Science and Technology 36, 141-163. doi:10.1016/S0165-232X(03)00008-9.

Vancoppenolle, M., Fichefet, T., Goosse, H., Bouillon, S., Madec, G., Morales Maqueda, M.A., 2009. Simulating the mass balance and salinity of Arctic and Antarctic sea ice. 1. Model description and validation. Ocean Modelling 27, 33-53. doi:10.1016/j.ocemod.2008.10.005. 
Vancoppenolle, M., Goosse, H., de Montety, A., Fichefet, T., Tremblay, B., Tison, J.L., 2010. Modeling brine and nutrient dynamics in Antarctic sea ice: the case of dissolved silica. Journal of Geophysical Research 115, C02005. doi:10.1029/2009JC005369.

Williams, G., Maksym, T., Wilkinson, J., Kunz, C., Murphy, C., Kimball, P., Singh, H., 2014. Thick and deformed Antarctic sea ice mapped with autonomous underwater vehicles. Nature Geoscience 8, 61-67. doi:10.1038/ngeo2299.

Worby, A., Massom, R., Allison, I., Lytle, V.I., Heil, P., 1998. Antarctic sea ice: Physical processes, interactions and variability. Antarctic Research Series, chap. East Antarctic sea ice: A review of its structure, properties and drift, AGU 74, $89-122$.

Worby, A.P., Geiger, C.A., Paget, M.J., Woert, M.L.V., Ackley, S.F., DeLiberty, T.L., 2008. The thickness distribution of Antarctic sea ice. Journal of Geophysical Research 113, C05S92. doi:.1029/2007JC004254,. 
Table 1: Physical constants.

\begin{tabular}{|c|c|c|c|c|}
\hline Symbol & Definition & Value & Units & Reference \\
\hline$c_{0}$ & Heat capacity (pure ice) & 2110 & $\mathrm{~J} /(\mathrm{kg} \cdot \mathrm{K})$ & Bitz and Lipscomb (1999) \\
\hline$c_{w}$ & Heat capacity (saltwater) & 3992 & $\mathrm{~J} /(\mathrm{kg} . \mathrm{K})$ & IOC et al. (2010) \\
\hline$L$ & Latent heat of fusion (pure ice) & $334 \times 10^{3}$ & $\mathrm{~J} / \mathrm{kg}$ & Bitz and Lipscomb (1999) \\
\hline$\mu_{\mathrm{NaCl}}$ & Linear dependence of liquidus ( $\mathrm{NaCl}$ ice) & 0.0598 & ${ }^{\circ} \mathrm{C} /(\mathrm{g} / \mathrm{kg})$ & Notz (2005b) \\
\hline$\mu_{s i}$ & Linear dependence of liquidus (sea ice) & 0.054 & ${ }^{\circ} \mathrm{C} /(\mathrm{g} / \mathrm{kg})$ & Notz (2005b) \\
\hline$\rho_{s}$ & Density (snow) & $100-600$ & $\mathrm{~kg} / \mathrm{m}^{3}$ & Massom et al. (2001) \\
\hline$\rho_{i}$ & Density (sea ice) & 950 & $\mathrm{~kg} / \mathrm{m}^{3}$ & This study \\
\hline
\end{tabular}




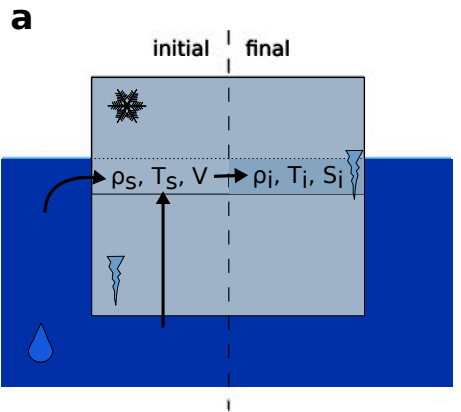

b

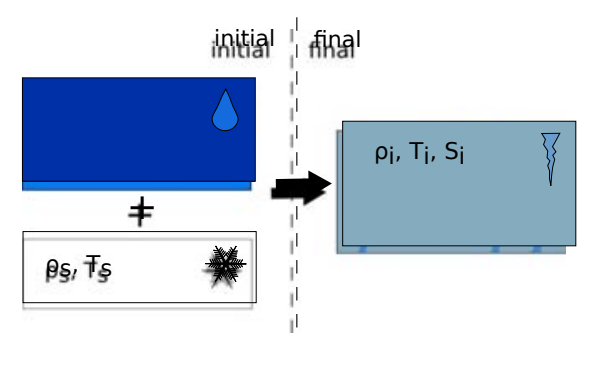

C

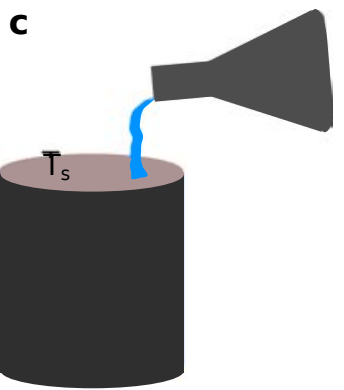

Figure 1: Schematics of a flooding event (a) in the field, (b) as viewed in sea-ice models, and (c) in the laboratory experiments described in this paper. $\rho$ represents density, $m$ mass, $V$ volume, $T$ temperature and $S$ salinity. The subscript $w$ stands for water, $i$ for ice and $s$ for snow. 


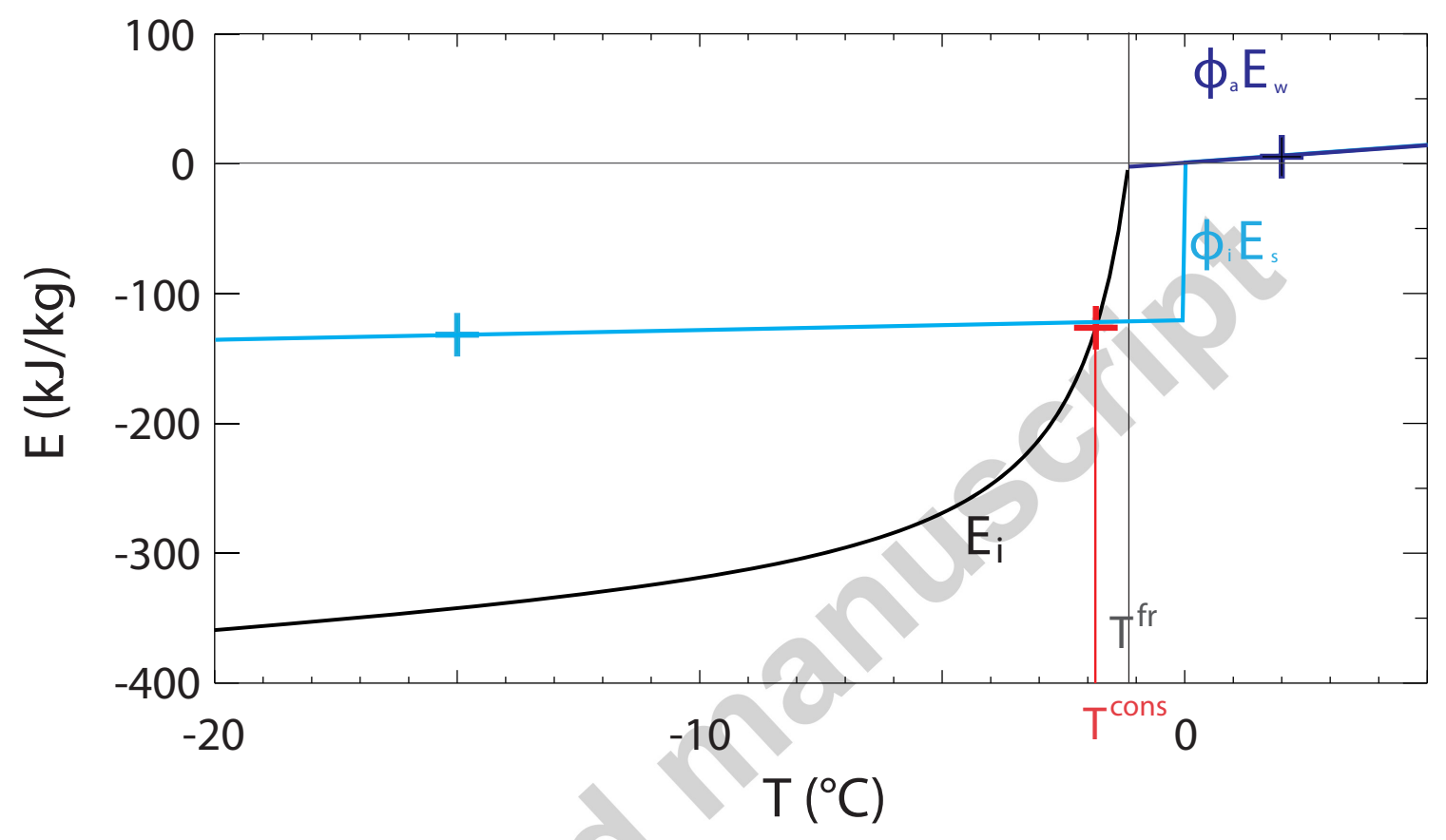

Figure 2: Enthalpy-temperature diagram for snow ice formation as represented in the fullyconserving approach (Schmidt et al., 2004, eq. 2b), showing the snow-ice enthalpy ( $E_{i}$, black line), as well as the weighted contributions of snow enthalpy $\left(\phi_{i} E_{s}\right.$, light blue line) and saltwater enthalpy ( $\phi_{a} E_{w}$, deep blue line). A sample experiment is depicted (crosses) where snow with $T_{s}=-15^{\circ} \mathrm{C}$ (light blue) is flooded by saltwater with $T_{w}=2^{\circ} \mathrm{C}$ (deep blue). The resulting snow-ice enthalpy is $\phi_{i} E_{s}+\phi_{a} E_{w}$ (red). The resulting snow-ice temperature $T^{\text {cons }}$ (eq. 3) can be graphically retrieved as the abscissa of the red cross. The freezing point of flooding saltwater $\left(T^{f r}\right.$, eq. प) is also indicated. The diagram was constructed using $\rho_{s}=330 \mathrm{~kg} / \mathrm{m}^{3}$ and $S_{w}=34 \mathrm{~g} / \mathrm{kg}$, giving, $\phi_{i}=0.35$, $\phi_{a}=0.65$ and $S_{i}=21.8 \mathrm{~g} / \mathrm{kg}$. 

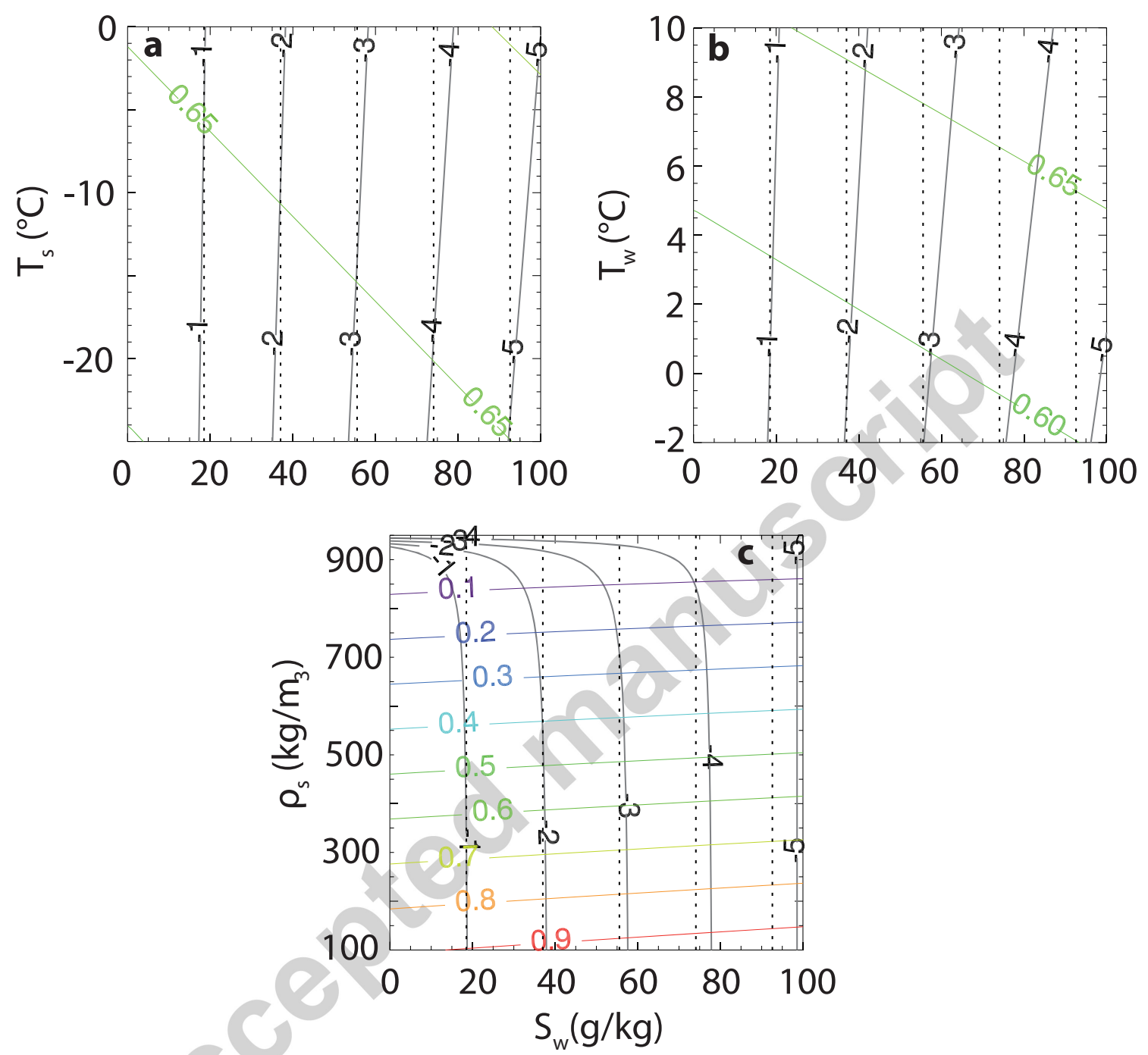

Figure 3: Snow-ice temperature (black) and brine fraction (color) isolines for various input parameter combinations, retrieved from the fully-conserving approach (eq. 2b Schmidt et al., 2004, solid lines). Black dashed lines represent the freezing point of flooding saltwater (eq. 1). In panel (a) $\rho_{s}=330 \mathrm{~kg} / \mathrm{m}^{3}$ and $T_{w}=0^{\circ} \mathrm{C}$; in (b) $\rho_{s}=330 \mathrm{~kg} / \mathrm{m}^{3}$ and $T_{s}=-5^{\circ} \mathrm{C}$ and in (c) $T_{w}=0^{\circ} \mathrm{C}$ and $T_{s}=-5^{\circ} \mathrm{C}$. Those values are assumed typical of natural conditions. 


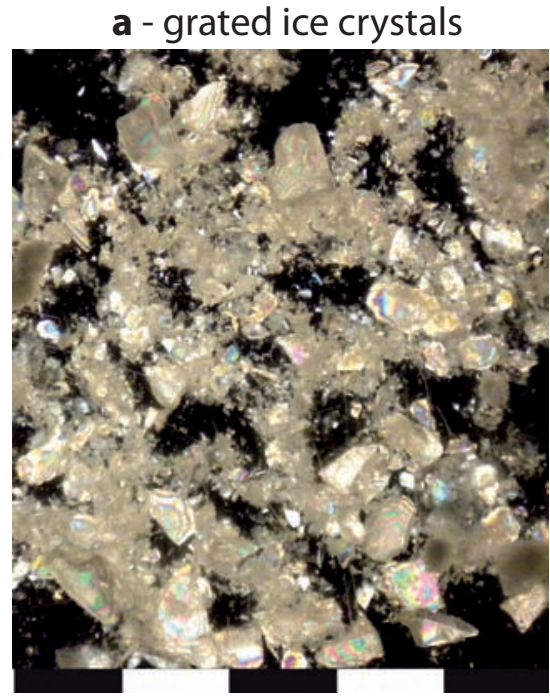

c - thin section (lab)

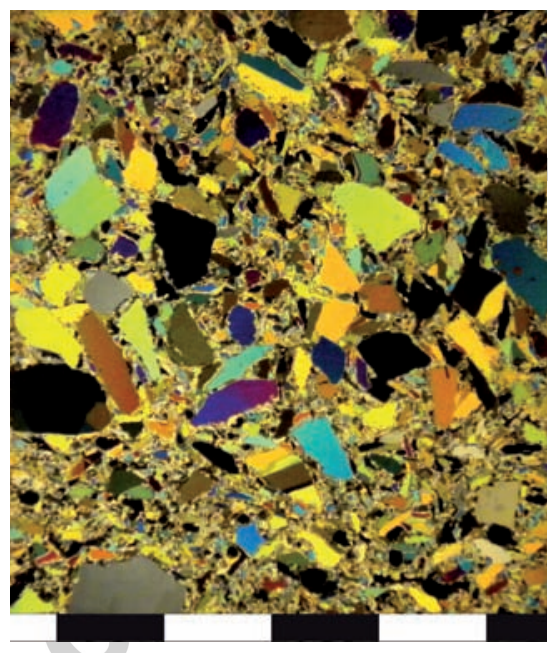

b - thick section (lab)

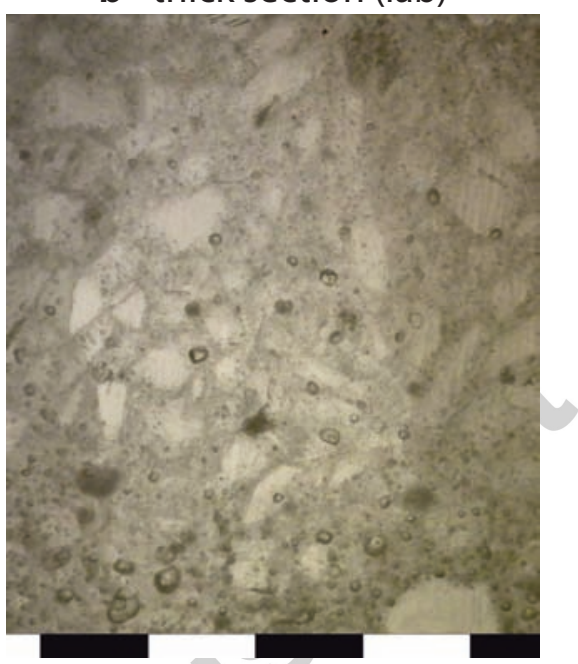

d - thin section (in situ)

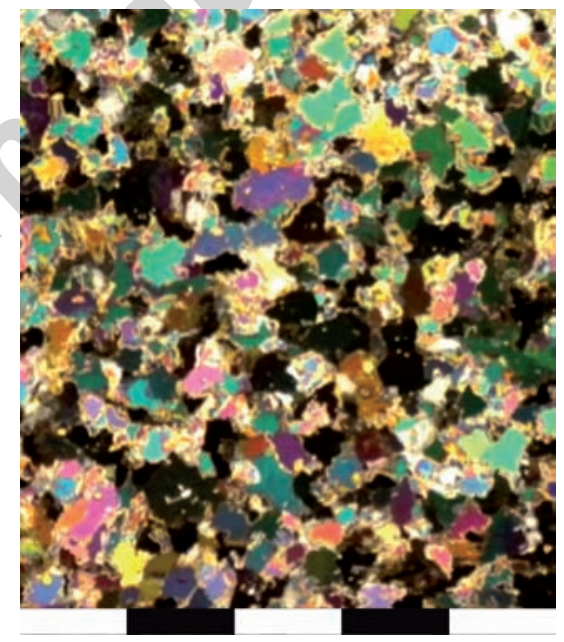

Figure 4: Cold room textural analysis of (a) unpacked grated ice crystals; (b) thick $(0.5 \mathrm{~cm})$ and (c) thin sections $(0.8 \mathrm{~mm})$ from synthetic snow ice (lab); (d) thin section $(0.8 \mathrm{~mm})$ from natural sea ice identified as snow ice from the SIMBA campaign, sampled at Liège site, station 2, Oct 8, 2007 (Lewis et al., 2011). The rules indicate 1-cm spacings. 


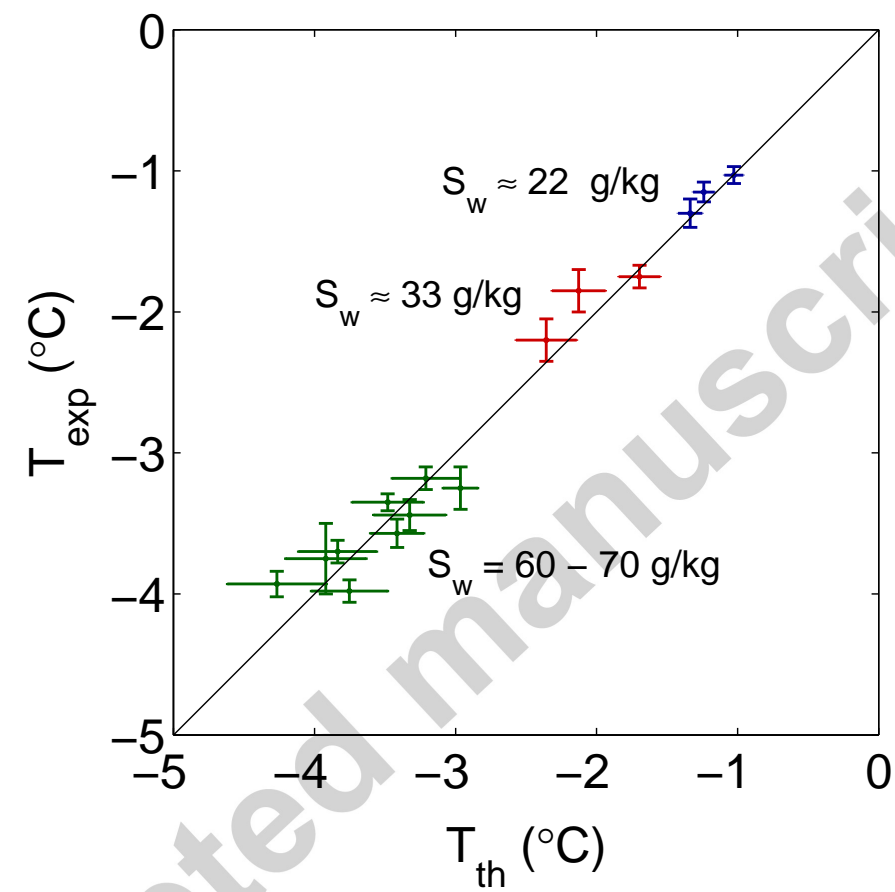

Figure 5: Snow-ice temperature: experimental versus retrieved (fully-conserving approach, Schmidt et al., 2004, eq. 3), for different sets of input physical parameters, and grouped for different saltwater salinities. The crosses represent the experimental and theoretical uncertainty range. 

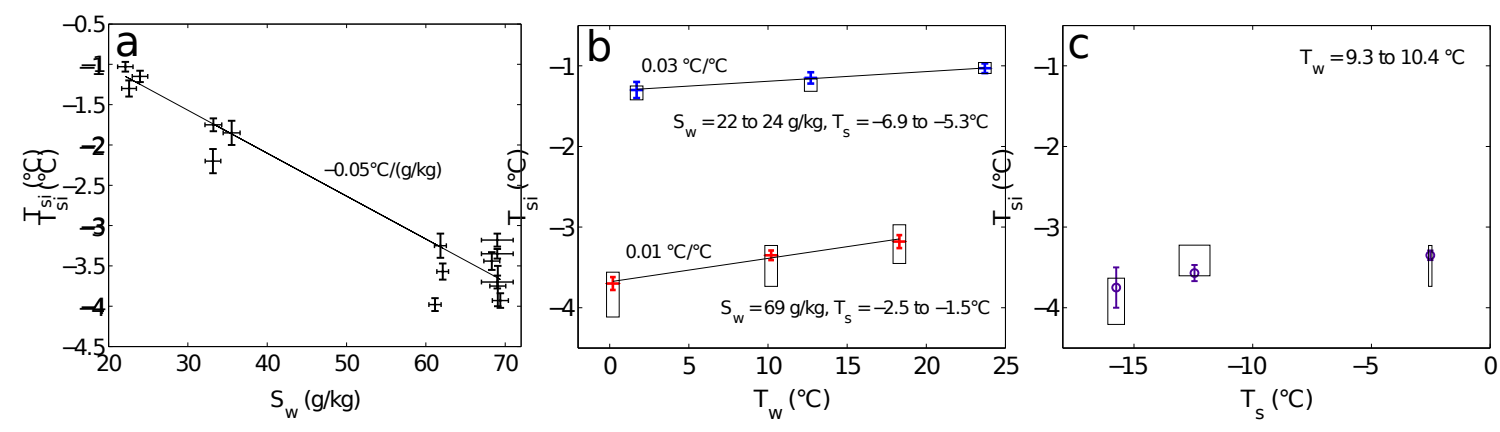

Figure 6: Observed snow-ice temperature versus (a) water salinity, (b) water temperature and (c) snow temperature in the laboratory experiments. The squares are the retrieved values (fullyconserving approach, Schmidt et al., 2004, eq. 3), including uncertainty. For each experiment we attempted to change a single parameter at a time, which was not easy to achieve and explains most of the scatter.

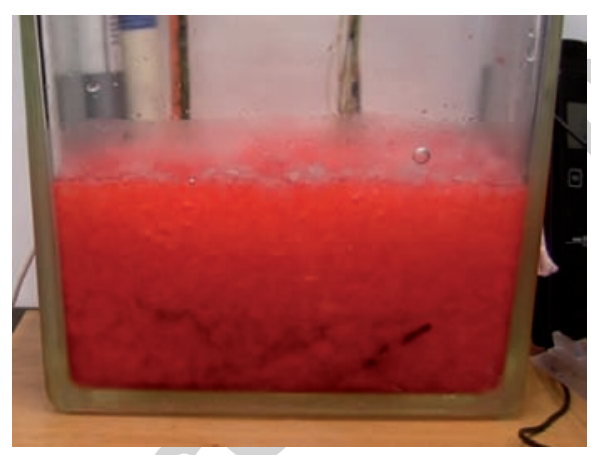

(a) Nearly consolidated ice

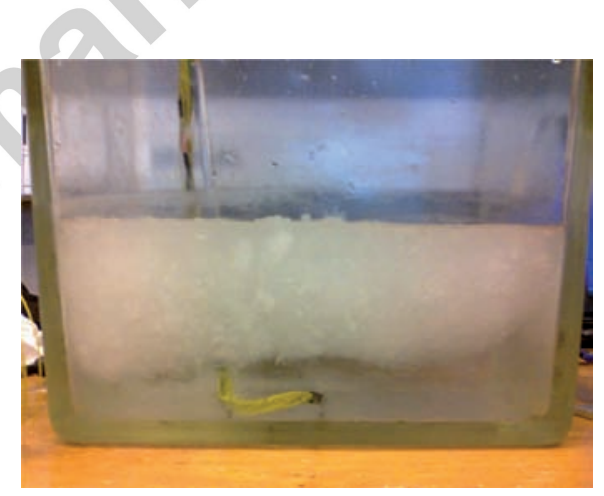

(b) High brine volume fraction and visible stratification effects

Figure 7: Impact of brine fraction on ice flotation, for two sample experiments performed in a glass container rather than in the cryogenic container for visualization purposes. In (a) the brine fraction is small enough to prevent flotation, hence the system reaches thermodynamic equilibrium. In (b) the brine fraction is $\approx 80 \%$, the ice matrix is not solid enough, stratification occurs and $\mathbf{H} \mathbf{2}$ is not verified. The ice on the left picture is red because of a dye. 


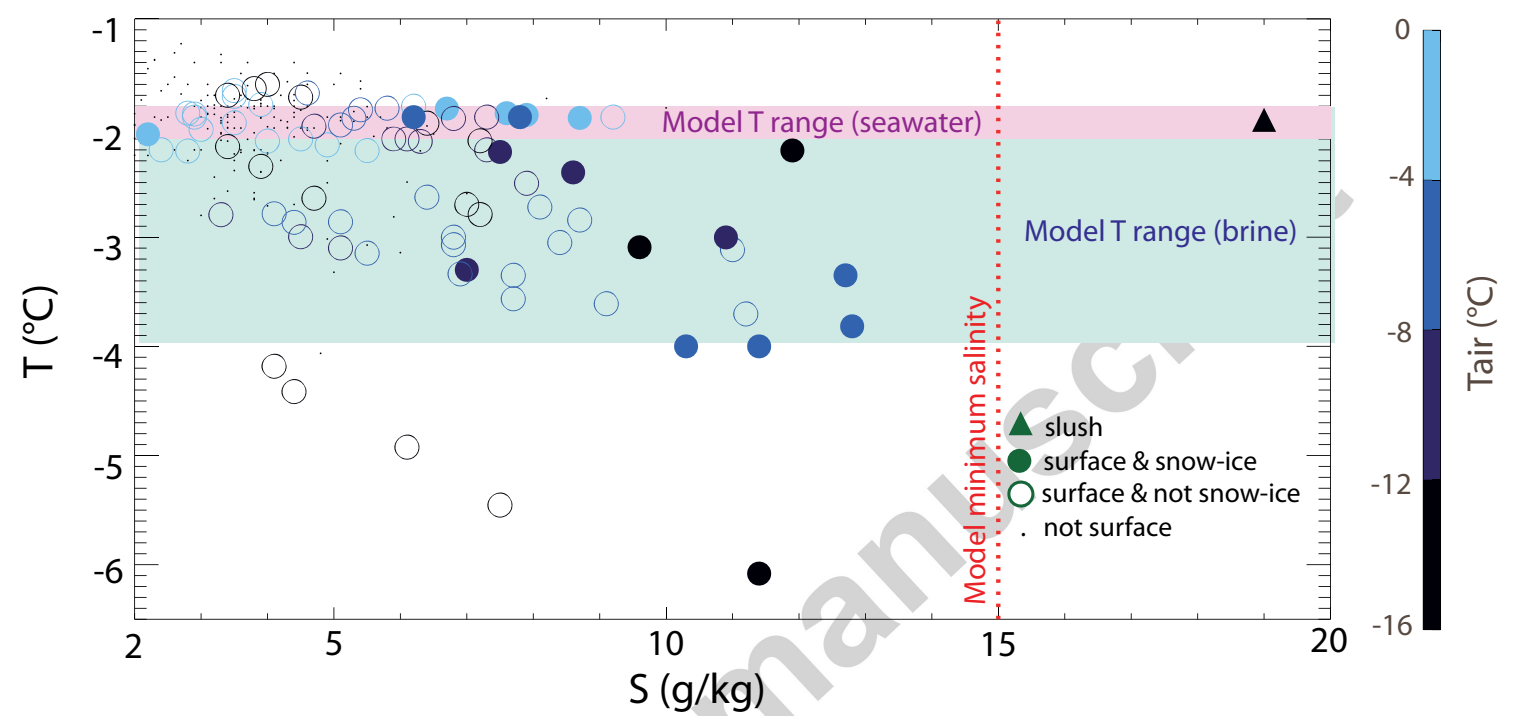

Figure 8: Sea-ice temperature versus salinity from the SIMBA samples: slush $(\triangle)$; deep ice-core sections $\left(z \geq h_{i} / 3, \cdot\right)$ and surface ice-core sections $\left(z<h_{i} / 3, \bigcirc\right)$. Filled symbols indicate samples classified as snow ice $\left(\delta^{18} O<-2 \%\right.$ and granular texture). The retrieved temperature and salinity ranges (fully-conserving approach, Schmidt et al., 2004, eq. 2b and 3) are also depicted. The pink and blue bands refer to the predicted temperature range (pink if the flooding water is seawater, blue if this is brine). The red vertical dotted line is the lowest expected snow-ice salinity (using $\rho_{s}=500 \mathrm{~kg} / \mathrm{m}^{3}$ and $\left.S_{w}=34 \mathrm{~g} / \mathrm{kg}\right)$. 
Table S1: Summary of experimental results. $T_{i}^{f r}=-\mu S_{w}$ (Eq. 1), and the $T_{i}^{c o n s}$ is retrieved from the fully-conserving approach (Schmidt et al., 2004, Eq. 3). Brine volume is computed from $\phi_{l}=-\mu S_{i} / T_{i}$, using measured $S_{i}$ and $T_{i}$. The last seven experiments have a brine fraction $\left(\phi_{l}\right)$ exceeding our model range of applicability $\left(>60 \mathrm{~kg} / \mathrm{m}^{3}\right)$, which is why the model experiment discrepancy is larger.

\begin{tabular}{|c|c|c|c|c|c|c|c|}
\hline$T_{w}\left( \pm 0.1^{\circ} \mathrm{C}\right)$ & $T_{s}\left({ }^{\circ} \mathrm{C}\right)$ & $\rho_{s}\left(\mathrm{~kg} / \mathrm{m}^{3}\right)$ & $S_{w}(\mathrm{~g} / \mathrm{kg})$ & $T_{i}^{e x p}\left({ }^{\circ} \mathrm{C}\right)$ & $T_{i}^{f r}\left( \pm 0.1^{\circ} \mathrm{C}\right)$ & $T_{i}^{c o n s}\left({ }^{\circ} \mathrm{C}\right)$ & $\phi_{l}(\%)$ \\
\hline 0.2 & $-1.5 \pm 0.1$ & f $561 \pm 11$ & $69 \pm 2$ & $-3.70 \pm 0.08$ & -4.1 & $-3.8 \pm 0.3$ & $46 \pm 3$ \\
\hline 10.2 & $-2.52 \pm 0.07$ & $561 \pm 11$ & $69 \pm 2$ & $-3.4 \pm 0.06$ & -4.1 & $-3.5 \pm 0.2$ & $51 \pm 4$ \\
\hline 18.3 & $-2.26 \pm 0.08$ & $567 \pm 11$ & $69 \pm 2$ & $-3.2 \pm 0.08$ & -4.1 & $-3.2 \pm 0.2$ & $52 \pm 4$ \\
\hline 3.0 & $-15.3 \pm 0.3$ & $578 \pm 12$ & $69 \pm 1$ & $-3.93 \pm 0.09$ & -4.1 & $-4.2 \pm 0.5$ & $34 \pm 3$ \\
\hline 10.4 & $-15.8 \pm 0.4$ & $578 \pm 12$ & $69 \pm 1$ & $-3.8 \pm 0.3$ & -4.1 & $-3.9 \pm 0.4$ & $36 \pm 4$ \\
\hline 17.2 & $-6.4 \pm 0.8$ & $578 \pm 12$ & $68 \pm 1$ & $-3.4 \pm 0.1$ & -4.1 & $-3.3 \pm 0.4$ & $40 \pm 3$ \\
\hline 6.1 & $-26.3 \pm 0.6$ & $582 \pm 12$ & $33 \pm 1$ & $-2.20 \pm 0.15$ & -2.0 & $-2.3 \pm 0.4$ & $45 \pm 6$ \\
\hline 11.9 & $-18.3 \pm 0.6$ & $582 \pm 12$ & $35 \pm 1$ & $-1.85 \pm 0.15$ & -2.1 & $-2.1 \pm 0.4$ & $38 \pm 7$ \\
\hline 23.0 & $-14.5 \pm 0.4$ & $582 \pm 12$ & $33 \pm 1$ & $-1.75 \pm 0.08$ & -2.0 & $-1.7 \pm 0.3$ & $36 \pm 6$ \\
\hline-1.2 & $-11.3 \pm 0.8$ & $500 \pm 15$ & $61.1 \pm 0.8$ & $-4.0 \pm 0.8$ & -3.7 & $-3.7 \pm 0.4$ & $40 \pm 2$ \\
\hline 9.3 & $-12.5 \pm 0.7$ & $515 \pm 10$ & $62.1 \pm 0.8$ & $-3.6 \pm 0.1$ & -3.7 & $-3.4 \pm 0.3$ & $45 \pm 2$ \\
\hline 20.8 & $-10.5 \pm 0.4$ & $494 \pm 8$ & $61.8 \pm 0.8$ & $-3.25 \pm 0.15$ & -3.7 & $-3.0 \pm 0.2$ & $62 \pm 3$ \\
\hline 1.0 & $-8.1 \pm 0.9$ & $549 \pm 13$ & $62 \pm 1$ & $-4.0 \pm 0.1$ & -3.7 & $-3.6 \pm 0.4$ & $44 \pm 3$ \\
\hline 10.4 & $-10 \pm 1$ & $540 \pm 15$ & $62 \pm 1$ & $-3.8 \pm 0.2$ & -3.7 & $-3.3 \pm 0.4$ & $40 \pm 3$ \\
\hline 21.0 & $-9.2 \pm 0.4$ & $549 \pm 14$ & $62 \pm 1$ & $-3.33 \pm 0.06$ & -3.7 & $-3.0 \pm 0.3$ & $50 \pm 4$ \\
\hline 3.7 & $-3.6 \pm 0.4$ & $484 \pm 22$ & $61.5 \pm 0.8$ & $-3.6 \pm 0.2$ & -3.7 & $-3.4 \pm 0.4$ & $45 \pm 2$ \\
\hline 11.7 & $-5.3 \pm 0.5$ & $489 \pm 10$ & $61.0 \pm 0.8$ & $-3.4 \pm 0.2$ & -3.6 & $-3.1 \pm 0.2$ & $51 \pm 3$ \\
\hline 18.6 & $-2.0 \pm 0.2$ & $462 \pm 9$ & $61.7 \pm 0.8$ & $-3.03 \pm 0.09$ & -3.7 & $-2.9 \pm 0.2$ & $50 \pm 2$ \\
\hline 23.7 & $-5.7 \pm 0.3$ & $400 \pm 8$ & $22 \pm 1$ & $-1.03 \pm 0.06$ & -1.3 & $-1.0 \pm 0.1$ & $66 \pm 11$ \\
\hline 12.7 & $-5.3 \pm 0.4$ & $396 \pm 8$ & $24 \pm 1$ & $-1.15 \pm 0.07$ & -1.4 & $-1.2 \pm 0.2$ & $63 \pm 10$ \\
\hline 1.7 & $-6.9 \pm 0.3$ & $402 \pm 8$ & $23 \pm 1$ & $-1.3 \pm 0.1$ & -1.4 & $-1.4 \pm 0.2$ & $63 \pm 9$ \\
\hline 2.3 & $-1.4 \pm 0.2$ & $332 \pm 7$ & $61.0 \pm 0.8$ & $-3.58 \pm 0.07$ & -3.6 & $-3.4 \pm 0.2$ & $59 \pm 3$ \\
\hline 10.2 & $-6.9 \pm 0.3$ & $344 \pm 7$ & $60.7 \pm 0.8$ & $-3.36 \pm 0.07$ & -3.6 & $-3.1 \pm 0.2$ & $66 \pm 3$ \\
\hline 20.5 & $-5.3 \pm 0.3$ & $370 \pm 6$ & $61.34 \pm 0.8$ & $-3.08 \pm 0.08$ & -3.7 & $-2.9 \pm 0.2$ & $65 \pm 4$ \\
\hline 9.0 & $-0.8 \pm 0.6$ & $438 \pm 4$ & $61.4 \pm 0.8$ & $-2.9 \pm 0.2$ & -3.7 & $-3.1 \pm 0.2$ & $69 \pm 4$ \\
\hline
\end{tabular}

